\title{
DEVELOPMENT OF A RAPID CAPILLARY ZONE ELECTROPHORESIS METHOD TO QUANTIFY LEVOFLOXACIN AND MELOXICAM FROM TRANSDERMAL THERAPEUTIC SYSTEMS
}

\author{
AURA RUSU ${ }^{a}$, PAULA ANTONOAEA ${ }^{a}$, ADRIANA CIURBA ${ }^{a, *}$, \\ MAGDALENA BÎRSAN ${ }^{b}$, GABRIEL HANCU ${ }^{\mathrm{a}}$, NICOLETA TODORAN ${ }^{\mathrm{a}}$
}

\begin{abstract}
Capillary zone electrophoresis (CZE) could be a useful technique for the quantification of active substances from transdermal therapeutic systems (TTSs). TTSs are pharmaceutical forms in development that may release one or more active substances with some significant advantages as increased compliance to treatment, avoidance of first hepatic passage and low manufacturing costs. A simple, reliable, efficient, and lowcost CZE method was developed and validated for the simultaneous determination of levofloxacin (fluoroquinolone) and meloxicam (non-steroidal anti-inflammatory) from TTSs. The selected experimental parameters were $50 \mathrm{mM}$ borax ( $\mathrm{pH}$ 9.3) as background electrolyte, $+25 \mathrm{kV}$ applied voltage, 50 mbar $/ 5$ seconds hydrodynamic injection and $40^{\circ} \mathrm{C}$ temperature, using an uncoated fused-silica capillary with $(51 \mathrm{~cm}$ total length/43 cm effective length, $50 \mu \mathrm{m}$ i.d.). CZE experiments were performed in less than four minutes with a resolution of 7.79 at a wavelength of $335 \mathrm{~nm}$. Validation of the method presented good linearity data, precision (RDS\% $<1$ for migration times and $\mathrm{RDS} \%<2$ for peaks area) and sensitivity (LOD 3.43 and 16.05 $\mu \mathrm{g} \cdot \mathrm{mL}^{-1}$, LOQ 10.38 and $54.55 \mu \mathrm{g} \cdot \mathrm{mL}^{-1}$ for levofloxacin and meloxicam, respectively). Recovery of the active substances ranged between $85.14 \%$ and $96.38 \%$. Our developed CZE method proved its applicability for analysis of the two substances from TTSs.
\end{abstract}

Keywords: levofloxacin, meloxicam, capillary zone electrophoresis, transdermal therapeutic systems

\footnotetext{
a University of Medicine, Pharmacy, Sciences and Technology of Târgu Mureş, Faculty of Pharmacy, 38 Gheorghe Marinescu str., RO-540139, Târgu Mureş, Romania

b "Grigore T. Popa", University of Medicine and Pharmacy of Iaşi, Faculty of Pharmacy, 16 Universitatii str., RO-700115, laşi, Romania,

*Corresponding author adriana.ciurba@umftgm.ro
} 


\section{INTRODUCTION}

Capillary electrophoresis (CE) is an analytical method increasingly used in the analysis of pharmaceutical products due to several advantages related to its simplicity, rapid method development and the low-costs of operation. Besides, this method may also be appropriate for the analysis of the complex samples, where analytes can be separated due to their different electrophoretic behaviour [1]. Capillary Zone Electrophoresis (CZE) is the simplest CE technique in which the analytes are separated using a simple buffer, without any additives, the separation taking place due to the differences between the own electrophoretic mobilities of the analytes. Our primary objective was the development, optimization and validation of a simple CZE method for the quantification of two active substances from new experimental transdermal therapeutic systems (TTSs).

TTSs are generally referred to as "patches". These are innovative pharmaceutical forms that may include one or more pharmaceutically active substances. Although there are many challenges in the TTS design (e.g. permeability and skin irritation) the advantages of using these devices are unquestionable as the administration of these pharmaceutical forms can improve the patient's adherence and compliance to treatment by reducing the frequency of dosing (a TTS per day up to a TTS per week) in the conditions where the first hepatic passage is avoided (thus requiring lower doses), which makes it possible to reduce both treatment and manufacturing costs $[2,3]$. The two selected active substances in this study are levofloxacin (LVF) and meloxicam (MLX) (Figure 1).<smiles>CC1COc2c(N3CCN(C)CC3)c(F)cc3c(=O)c(C(=O)O)cn1c23</smiles><smiles>Cc1cnc(NC(=O)C2=C(O)c3ccccc3S(=O)(=O)N2C)s1</smiles>

Figure 1. Chemical structures of LVF (1) and MEL (2). 
LVF ((S)-9-fluoro-2,3-dihydro-3-methyl-10-(4-methylpiperazin-1-yl)-7oxo-7H-pyrido[1,2,3-de]-1,4-benzoxazine-6-carboxylic acid), is a third-generation fluoroquinolone, the levorotatory isomer of ofloxacin. The antibacterial spectrum of LVF includes Gram-positive bacteria, Gram-negative bacteria and atypical bacteria. LVF is indicated in the treatment of a variety of bacterial infections and is administered both internally and externally $[4,5]$. Several studies and patents for topical pharmaceutical products with LVF are already published in the literature [6-9].

MLX (4-hydroxy-2-methyl-N-(5-methylthiazol-2-yl)-2H-1,2-benzothiazine-3-carboxamide 1,1-dioxide) is an effective non-steroidal anti-inflammatory drug (NSAID) which is used in the treatment of rheumatoid arthritis, osteoarthritis, and ankylosing spondylitis. In the last decade, several studies have been published regarding preparation and testing TTSs containing $M L X$ with encouraging results in skin permeability [10-13].

Co-administration of a fluoroquinolone with an NSAID in a TTS may be beneficial in both local and systemic treatment. However, few previous studies have followed this possible association. At the administration of $M L X$, a significant decrease of plasma antioxidant activity occurs and also when LVF is co-administered with MLX in rabbits; the body weight of the rabbits was not influenced [14]. Other similar studies present the effects on oxidative balance in blood and the immunolocalisation of ABCG-2 transporter protein in rabbit retina $[15,16]$. Another research shows that co-administration of MLX with ofloxacin in goats does not require any adjustment in dosage regimens, but in another study addressed on cross-bred calves, it is recommended the change of LVF dosage when is co-administered with MLX $[17,18]$.

The aim of our study was the development of a new CZE method applicable for the simultaneous quantification of two active substances (LVF and MLX) from three different experimental TTS formula.

\section{RESULTS AND DISCUSSION}

Several previously published CE methods analysed both LVF and MLX. The used background electrolyte (BGE) solutions are summarized in Table 1. 
Table 1. The BGE composition used in different CE methods for the analysis of LVF and MLX (Ref. - References).

\begin{tabular}{|l|c|l|c|}
\hline \multicolumn{2}{|c|}{ LVF } & \multicolumn{2}{c|}{ MLX } \\
\hline \multicolumn{1}{|c|}{ BGE composition } & Ref. & \multicolumn{1}{c|}{ BGE composition } & Ref. \\
\hline $25 \mathrm{mM}$ borax (pH 9.2) & {$[19]$} & $100 \mathrm{mM}$ borax buffer $(\mathrm{pH} \mathrm{8.5)}$ & {$[22]$} \\
\hline $\begin{array}{l}\text { 60 mM hydroxylpropyl-beta- } \\
\text { cyclodextrin in 50 mM phosphate } \\
\text { buffer (pH 2.30) }\end{array}$ & {$[20]$} & $\begin{array}{l}10 \mathrm{mM} \text { Tris buffer with 60 mM } \\
\text { sodium octane-sulfonate and } \\
20 \% \text { acetonitrile (pH 11) }\end{array}$ & {$[23]$} \\
\hline $\begin{array}{l}\text { 20 mM phosphate buffered (pH } \\
8.0)\end{array}$ & {$\left[\begin{array}{l}\text { 21] } \\
18 \mathrm{mM} \text { sodium phosphate } \\
\text { buffer (pH 5.90) }\end{array}\right.$} & {$[24]$} \\
\hline
\end{tabular}

The $p K_{\mathrm{a}}$ values for LVF and MLX are very similar (as HA - protonated form a weak acid). Also, the results of previous research regarding the separation of a large number of antibacterial quinolones have been taken into consideration, research in which the selected BGE was $25 \mathrm{mM}$ borax [25]. By correlating the information presented in Table 1 with the physical properties of the two active substances comprised in Table 2 it was considered that an appropriate BGE for our separation method might be a solution containing $25 \mathrm{mM}$ borax at $\mathrm{pH}$ 9.3.

Table 2. Physical properties of LVF and MLX (MW - molecular weight, $\mathrm{HA}$ - a protonated form a weak acid, $\mathrm{BH}^{+}$-a protonated form of a weak base, DMF - dimethylformamide).

\begin{tabular}{|c|c|c|c|c|c|}
\hline Compound & $\begin{array}{c}\mathrm{MW} \\
\left(\mathrm{g} \cdot \mathrm{mol}^{-1}\right)\end{array}$ & Solubility & $p K_{a}$ & $\log P$ & Ref. \\
\hline LVF & 361.37 & $\begin{array}{l}\text { freely soluble in glacial } \\
\text { acetic acid, chloroform, } \\
\text { sparingly soluble in } \\
\text { water }\end{array}$ & $\begin{array}{c}(\mathrm{HA}) 5.59 \\
\left(\mathrm{BH}^{+}\right) 7.94\end{array}$ & 1.268 & {$[26,27]$} \\
\hline MLX & 351.4 & $\begin{array}{l}\text { insoluble in water, } \\
\text { soluble in DMF, very } \\
\text { slightly in methanol; } \\
1.736 \mathrm{M} \cdot 10^{-3} \text { (in } 0.2 \mathrm{M} \\
\text { phosphate buffer pH } \\
7.4 \text { at } 37^{\circ} \mathrm{C} \text { ) }\end{array}$ & $\begin{array}{c}(\mathrm{HA}) 4.5 \\
\left(\mathrm{BH}^{+}\right) 3.05\end{array}$ & 2.71 & [28-31] \\
\hline
\end{tabular}


LVF shows maximum absorption in UV at $300 \mathrm{~nm}$ and an additional maximum absorption of $327 \mathrm{~nm}[32,33]$. MLX shows maximum absorption in UV light at $360 \mathrm{~nm}[34,35]$. Thereby, the appropriate wavelength for the determination of both substances was set at $335 \mathrm{~nm}$. To optimise the CZE method, the influence of BGE concentration, $\mathrm{pH}$, applied voltage, injection pressure, injection time, and system temperature on the separation were analysed systematically using a "one factor at a time" optimization approach. The maximum current flow was set to $150 \mu \mathrm{A}$, to avoid instability of the electrophoretic system [36].

Figure 2 shows the influence of BGE concentration, $\mathrm{pH}$ of the BGE, voltage, and temperature on the migration times in the optimisation process.

The $\mathrm{pH}$ of the BGE was adjusted by addition of $\mathrm{NaOH} 1 \mathrm{M}$ and boric acid $1 \mathrm{M}$. Thus, the best separation conditions were selected to provide adequate migration time and good peak symmetry, resolution, and selectivity (Figure 3).

A)
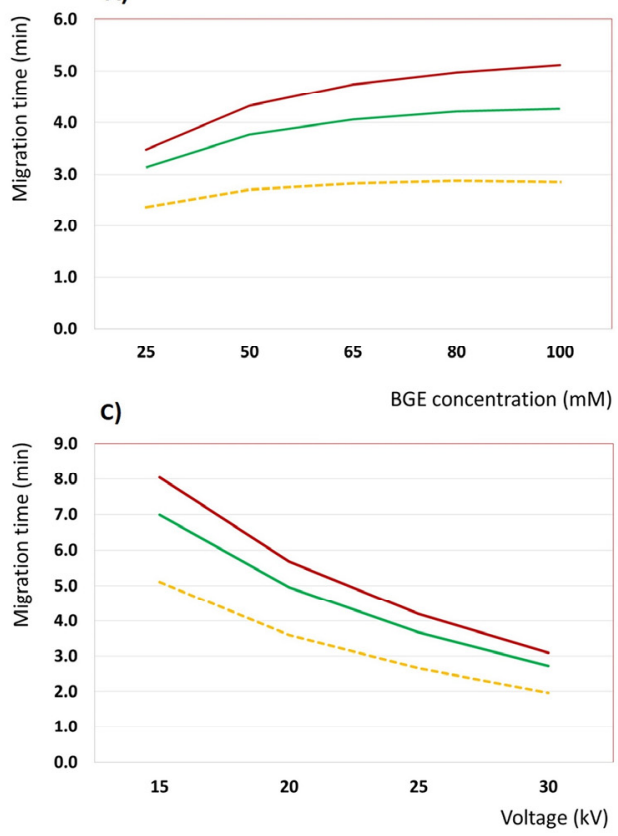

B)

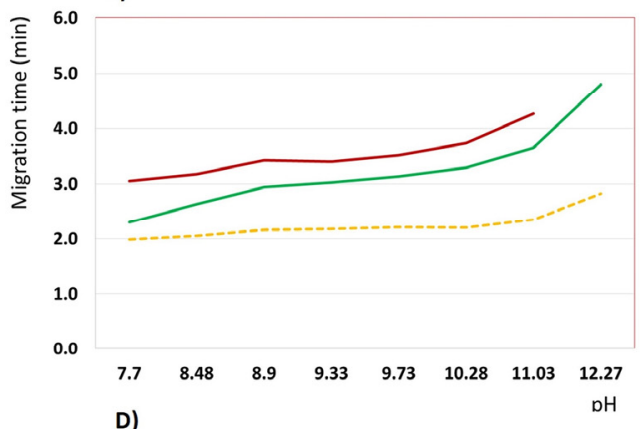

D)

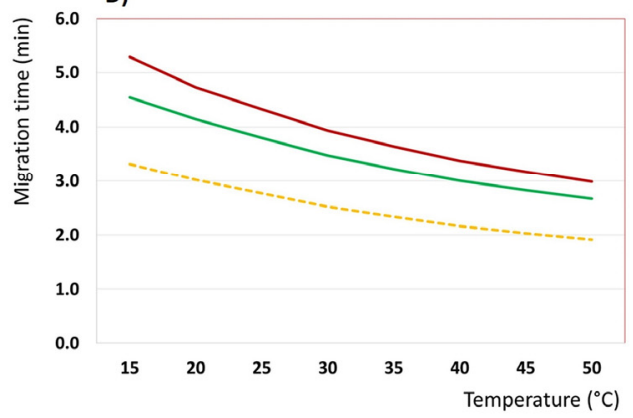

Figure 2. The influence of A) BGE concentration, B) pH of the BGE, C) voltage and $\mathbf{D}$ ) temperature on the migration times in the optimisation process of the CZE method. 
The best separation using the optimised analytical conditions of LVF and MLX by CZE is represented in Figure 4 and the parameters of the CZE experiment in Table 3.

Method validation. The method was verified regarding validation parameters according to ICH Q2(R1) Guideline [37]. The specificity of the method was proved using the UV spectra and the migration times of the analytes Thereby, the LVF and MLX could be identified simultaneously from a mixture without any interference. The migration order was established as being: LVF followed by MLX. As in the preliminary experiments, the EOF migration time values were constantly similar; we considered that it was not necessary to use an internal standard. Linearity and detectability (limit of detection - LOD, limit of quantification - LOQ) of the method were also determined. Thus, an excellent linear signal-concentration relationship for the two compounds was demonstrated (Table 4).

A)

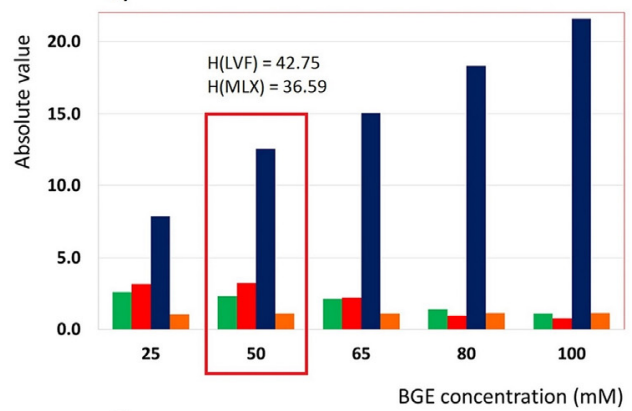

c)

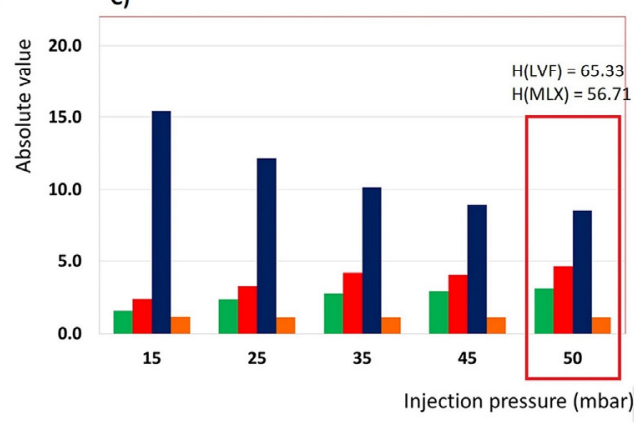

B)

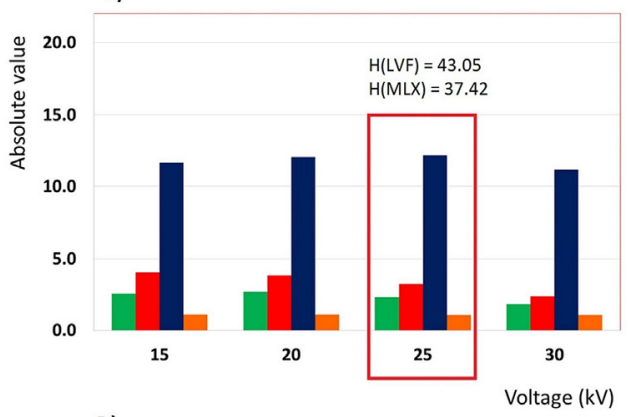

D)

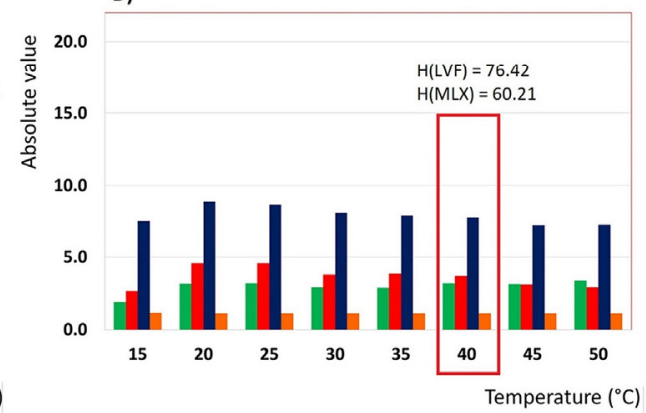

Figure 3. Variation of symmetry, resolution and selectivity of analytes signals in terms of A) BGE concentration, B) voltage, C) injection pressure and D) temperature (Sym. - symmetry, Rs - resolution, Sel. - selectivity, $H$ - height of peak). 


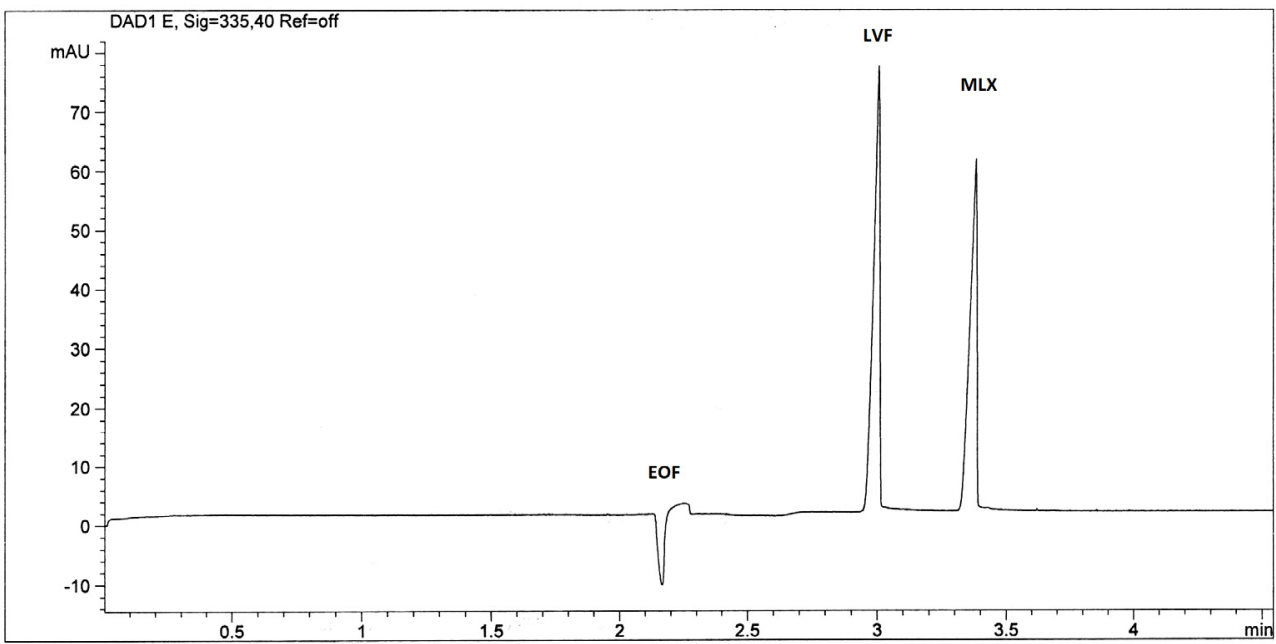

Figure 4. The electropherogram of LVF and MLX separation (BGE $50 \mathrm{mM}$ borax, +25 kV applied voltage, $50 \mathrm{mbar} / 5$ seconds hydrodynamic injection, $40^{\circ} \mathrm{C}$ temperature).

Table 3. Electrophoretic parameters of LVF and MLX separation using the optimized analytical conditions (EOF migration time 2.17 , concentration $0.5 \mathrm{mg}$. $\mathrm{mL}-1$ ) (MT - migration time, $A$ - area, $H$ - height, Sym. - symmetry, $P$ - plates, Res. - resolution, Sel. - selectivity).

\begin{tabular}{|l|c|c|c|c|c|c|c|}
\hline Compounds & $\begin{array}{c}\text { MT } \\
(\mathrm{min})\end{array}$ & $\begin{array}{c}\text { A } \\
\left(\mathrm{mAU}^{*} \mathrm{~s}\right)\end{array}$ & $\begin{array}{c}\mathbf{H} \\
(\mathrm{mAU})\end{array}$ & Sym. & $\mathbf{P}$ & Res. & Sel. \\
\hline LVF & 3.00 & 128622 & 76.30 & 3.19 & 67497 & - & - \\
\hline MLX & 3.38 & 112586 & 57.99 & 3.71 & 73023 & 7.79 & 1.13 \\
\hline
\end{tabular}

LOD and LOQ were calculated based on the standard deviation of the response (Sy.x) and the slope (S). Excellent correlation coefficients and low detection limits for LVF and MLX were obtained. The LOD and LOQ for LVF are comparable with those previously published in the literature [19], while for MLX are slightly higher than other in published materials [23]. The concentration range of the method is between $6.25 \mu \mathrm{g} \cdot \mathrm{mL}^{-1}-1000 \mu \mathrm{g} \cdot \mathrm{mL}^{-1}$. Also, the robustness of the CZE method is supported by the variation of internal (system temperature, applied voltage, injection parameters) and external (BGE composition, concentration, $\mathrm{pH}$ ) parameters in the optimisation part of the research. 
Table 4. Linearity and detection limits of the separation CZE method.

\begin{tabular}{|c|c|c|}
\hline $\begin{array}{c}\text { Linearity parameters and } \\
\text { detection limits }\end{array}$ & LVF & MLX \\
\hline Regression equation & $y=267.44 x+0.1345$ & $y=238.48 x-0.8388$ \\
\hline Correlation coefficient & 0.9990 & 0.9983 \\
\hline Y intercept & 0.1345 & -0.8388 \\
\hline Slope of the regression line (S) & 267.44 & 238.48 \\
\hline $\begin{array}{l}\text { Standard deviation of residuals } \\
\text { from the line (Sy.x) }\end{array}$ & 0.2777 & 1.3010 \\
\hline $\begin{array}{l}\operatorname{LOD}\left(\mu \mathrm{g} \cdot \mathrm{mL}^{-1}\right), \\
\text { calculated LOD }=\frac{8.8 S_{y S x}}{s}\end{array}$ & 3.43 & 16.05 \\
\hline $\begin{array}{l}\mathrm{LOQ}\left(\mu \mathrm{g} \cdot \mathrm{mL}^{-1}\right) \\
\text { calculated } \mathrm{LOQ}=\frac{10 \mathrm{syx}}{s}\end{array}$ & 10.38 & 54.55 \\
\hline
\end{tabular}

Table 5. The obtained RDS\% values for intra-day and inter-day precision (Conc. concentration, $R S D$ - residual standard deviation).

\begin{tabular}{|c|c|c|c|c|c|c|c|}
\hline \multirow[t]{2}{*}{ Compound } & \multirow[t]{2}{*}{$\begin{array}{c}\text { Conc. } \\
\left(\mu \mathrm{g} \cdot \mathrm{mL}^{-1}\right)\end{array}$} & \multicolumn{3}{|c|}{$\begin{array}{l}\text { Intra-day precision } \\
(\text { RSD\%) } n=6\end{array}$} & \multicolumn{3}{|c|}{$\begin{array}{c}\text { Inter-day precision } \\
\text { (RSD\%) } n=18 \text {, days } 3\end{array}$} \\
\hline & & $\mathbf{M T}_{\text {EOF }}$ & MT & A & $\mathbf{M T}_{\text {EOF }}$ & MT & A \\
\hline \multirow[t]{3}{*}{ LVF } & 500 & 0.228 & 0.167 & 1.456 & 0.849 & 0.824 & 1.396 \\
\hline & 300 & 0.765 & 0.807 & 1.366 & 0.738 & 0.629 & 1.969 \\
\hline & 100 & 0.218 & 0.273 & 1.514 & 0.378 & 0.398 & 1.740 \\
\hline \multirow[t]{3}{*}{ MLX } & 500 & 0.228 & 0.219 & 1.401 & 0.849 & 0.623 & 1.353 \\
\hline & 300 & 0.765 & 0.699 & 1.977 & 0.738 & 0.562 & 1.982 \\
\hline & 100 & 0.218 & 0.299 & 0.423 & 0.378 & 0.465 & 1.963 \\
\hline
\end{tabular}

The precision of the method was evaluated regarding repeatability and intermediate precision (Table 5). The obtained RDS\% values are comparable with previously published data and support a good precision (intra-day and inter-day) of the method [19,23,24].

Application of the CZE method for the quantification of LVF and MLX from TTSs. Three experimental TTSs containing LVF and MLX (Table 6) were evaluated using the optimized CZE method. Dissolving the TTSs in the appropriate solvent represented a significant challenge taking into consideration both active substances and excipients. Ethylcellulose $(E C)$ is insoluble in water but is freely soluble in chloroform. If EC contains 
not less than $46.5 \%$ of ethoxy groups, this is freely soluble in ethanol $\left(96^{\circ}\right)$ and methanol. Hydroxypropyl methylcellulose (HPMC) is soluble in cold water, practically insoluble in chloroform, ethanol $\left(96^{\circ}\right)$ but soluble in a mixture of ethanol and dichloromethane, methanol and dichloromethane, water and ethanol $\left(96^{\circ}\right)$ [38]. The TTS samples mentioned in Table 6 were introduced in $25 \mathrm{~mL}$ volumetric flasks and dissolved in a mixture of organic solvents, with or without distilled water. Based on known solubility's of LVF, $\mathrm{MLX}$, and polymers, several combinations of solvents were tested to obtain an appropriate solution for injection in the CE system.

Table 6. Composition of three experimental TTSs (HPMC E5 hydroxypropylmethylcellulose type E5, HPMC 15000 hydroxypropylmethylcellulose type 15000, EC 10 - ethylcellulose type 10).

\begin{tabular}{|l|c|c|c|}
\hline Components (m/m \%) & TTS 1 & TTS 2 & TTS 3 \\
\hline LVF & 0.5 & 0.5 & 0.5 \\
\hline MLX & 0.5 & 0.5 & 0.5 \\
\hline HPMC E5 & 3 & - & - \\
\hline HPMC 15000 & - & 2 & 1 \\
\hline EC 10 & - & - & 1 \\
\hline Ethanol (96\% v/v) & 30 & 30 & 30 \\
\hline Propylene glycol & 10 & 10 & 10 \\
\hline Polysorbate 20 & 1 & 1 & \\
\hline Distilled water & up to 100 & up to 100 & up to 100 \\
\hline
\end{tabular}

The solvent systems used were as follows: for TTS 1 - $2 \mathrm{ml} \mathrm{DMF,} 9 \mathrm{ml}$ ethanol, and distilled water up to $100 \mathrm{ml}$; for TTS $2-2 \mathrm{ml}$ DMF, $2 \mathrm{ml}$ chloroform, and ethanol : dichloromethane (1:1) up to $100 \mathrm{ml}$; and for TTS 3 $2 \mathrm{ml}$ DMF, $5 \mathrm{ml}$ chloroform, $5 \mathrm{ml}$ methanol, and ethanol : dichloromethane (1:1) up to $100 \mathrm{ml}$. After 20 minutes stirring on the ultrasonic vibration, the mixtures were filtrated through $90 \mathrm{~mm}$ Whatman $®$ qualitative filter paper and diluted adequately with methanol (theoretical concentration of the active substances in samples is $0.1 \mathrm{mg} \mathrm{mL}^{-1}$ ). Although HPMC is soluble in a mixture of water and ethanol $(96 \% \mathrm{v} / \mathrm{v})$ the samples of TTS 2 and TTS 3 did not dissolve. The bulky precipitates were filtered, and the obtained solutions were additionally diluted with methanol. The collected quantitative results were unsatisfactory probably due to the retention of active substances in the precipitate. The obtained recovery results for LVF were satisfactory for all three experimental TTSs; however, MLX recovery values were lower (Table 7). According to some authors, recovery testing tends to be less critical, as long as the values of detection limits, precision and accuracy are acceptable [39]. 
Table 7. The composition of three experimental TTSs.

\begin{tabular}{|c|c|c|c|c|}
\hline TTSs & $\begin{array}{c}\text { Active } \\
\text { substance }\end{array}$ & $\begin{array}{c}\text { Theoretical } \\
\text { concentration } \\
\left(\mathrm{mg} \cdot \mathrm{mL}^{-1}\right)\end{array}$ & $\begin{array}{c}\text { Found } \\
\text { concentration } \\
\left(\mathrm{mg} \cdot \mathrm{mL}^{-1}\right)\end{array}$ & $\begin{array}{c}\text { Recovery (\%) } \\
\mathbf{\pm} \text { SD }\end{array}$ \\
\hline 1 & LVF & 0.1 & 0.096 & $96.38 \pm 4.37$ \\
\hline & $\mathrm{MLX}$ & 0.1 & 0.091 & $91.23 \pm 7.76$ \\
\hline 2 & $\mathrm{LVF}$ & 0.1 & 0.091 & $91.31 \pm 5.05$ \\
\hline & $\mathrm{MLX}$ & 0.1 & 0.088 & $90.03 \pm 9.45$ \\
\hline 3 & $\mathrm{LVF}$ & 0.1 & 0.090 & $90.10 \pm 5.23$ \\
\hline & $\mathrm{MLX}$ & 0.1 & 0.085 & $85.14 \pm 4.63$ \\
\hline
\end{tabular}

\section{CONCLUSIONS}

The developed CZE method proved to be appropriate to quantify the LVF and MLX simultaneously from TTSs. A BGE containing $50 \mathrm{mM}$ borax $(\mathrm{pH}$ 9.3) was used and the following optimised experimental conditions were applied: +25 kV applied voltage, $50 \mathrm{mbar} / 5$ seconds hydrodynamic injection, $40^{\circ} \mathrm{C}$ temperature, detection at a wavelength of $335 \mathrm{~nm}$. The method validation parameters have been verified and also the recovery of the active substances. The main advantages of this new method consist in its simplicity, rapidity (under four minutes), and low volumes consumption of solvents and analytes with consequently low costs of operation. Thus, we consider that our newly developed CZE method may be an alternative to classical HPLC in quantitative determinations of TTSs.

\section{EXPERIMENTAL SECTION}

Apparatus and chemicals. The CZE experiments were performed on an Agilent 1600 CE (with diode-array detector). The software used to process the data was Chemstation 7.01 (Agilent). An uncoated fused-silica capillary (Agilent) with $51 \mathrm{~cm}$ total length (43 cm effective length) and 50 $\mu \mathrm{m}$ internal diameter was used in the experiments. The $\mathrm{pH}$ of the samples was measured with a Hanna Instruments HI2215 pH-meter.

Active substances and polymers were supplied as follows: LVF and EC 10 (EC $10 \mathrm{mPa} \cdot \mathrm{s}$ ) from Sigma Aldrich Co. (Germany), MLX from Techno Drugs \& Intermediates Ltd. (India), HPMC 15000 (Metolose 90SH - 15000 $\mathrm{mPa} \cdot \mathrm{s})$ from Shin-Etsu Chemical Co., Ltd. (Tokyo, Japan), and HPMC E5 (Methocel E5 - $5 \mathrm{mPa} \cdot \mathrm{s}$ ) from Dow Chemical Co. (Midland, USA). All chemicals and solvents were of analytical reagent grade, and ultrapure water was obtained using a Millipore Direct-QS water distiller. 
The stock solutions were prepared daily using methanol for LVF and a mixture of methanol - DMF in ratio 9:1 for MLX, at a concentration of 1 $\mathrm{mg} \mathrm{mL}-1$. The solutions were kept at $+4^{\circ} \mathrm{C}$ in the refrigerator and diluted with methanol to obtain the appropriate concentrations.

Capillary preconditioning and conditioning. To ensure optimal run-to-run analytical conditions, reproducible migration times and a constant EOF, the capillary was conditioned by flushing with $1 \mathrm{M} \mathrm{NaOH}(20 \mathrm{~min})$, ultra-pure water ( $5 \mathrm{~min})$, and BGE (20 $\mathrm{min}$ ) at the beginning of each day. Between experiments, the capillary was preconditioned by flushing with BGE (2 min).

Preparation of TTSs. The samples of TTSs were obtained in the form of the thin matrices (polymeric films) by casting and solvent evaporation technique, according to a previously published method [40].

\section{ACKNOWLEDGEMENTS}

Funding supported this research through the Internal Research Grant from the University of Medicine and Pharmacy of Târgu Mureş (contract no. 275/6/11.01.2017).

\section{REFERENCES}

1. S. Orlandini, R. Gotti, S. Furlanetto, Journal of Pharmaceutical and Biomedical Analysis, 2014, 87, 290.

2. K.S. Paudel, M. Milewski, C.L. Swadley, N.K. Brogden, P. Ghosh, A.L. Stinchcomb, Therapeutic Delivery, 2010, 1, 109.

3. K. Kathe, H. Kathpalia, Asian Journal of Pharmaceutical Sciences, 2017, 12, 487.

4. A.M. Noreddin, W.F. Elkhatib, K.M. Cunnion, G.G. Zhanel, Drug, Healthcare and Patient Safety, 2011, 3, 59.

5. G.M. Keating, Drugs, 2009, 69, 1267.

6. P. Gao, X. Wang, S. Huang, Y. Wang, J. Guan, Y. Li, Z. Tao, Journal of Biomedical Engineering, 2014, 31, 806.

7. C. Wang, H. Fu, L. Chen, L. Zhang, R. Liu, Q. Liang, Patent No. CN107224425-A, 2017.

8. Nazar M.F., Saleem M.A., Bajwa S.N., Yameen B., Ashfaq M., Zafar M.N., M. Zubair, The Journal of Physical Chemistry B, 2017, 121, 437.

9. J.R. Ray, Patent No. US2018147212-A1, 2018. 
10. M. Ochi, K. Kimura, A. Kanda, T. Kawachi, A. Matsuda, K. Yuminoki, Hashimoto N. AAPS PharmSciTech, 2016, 17, 932.

11. J. Chen, Y. Gao, Drug Delivery, 2016, 23, 3146.

12. W. Wei, X. Li, A. Liu, D. Jing, L. Li, Patent No. CN106551918-A, 2017.

13. Y. Sun, X. Xu, M. Yao, Patent No. CN106924223-A, 2017.

14. A.M. Khan, S. Rampal, Veterinary World, 2013, 6, 950.

15. A.M. Khan, S. Rampal, N.K. Sood, Human \& Experimental Toxicology. 2017, $36,42$.

16. A.M. Khan, S. Rampal, N.K. Sood, Environmental Science and Pollution Research, 2018, 25, 8853.

17. V.K. Dumka, H. Singh, A.K. Srivastava, Environmental Toxicology and Pharmacology, 2008, 26, 56.

18. R.S. Yadav, S.K. Garg, A. Rahal, Veterinarski Arhiv, 2014, 84, 625.

19. H. Sun, Y. Zuo, Current analytical chemistry, 2013, 9, 157.

20. Y.-H. Tsai, M.-J. Bair, C.-C. Hu, Journal of the Chinese Chemical Society, 2007, 54, 991.

21. Y.M. Liu, J.T. Cao, W. Tian, Y.L. Zheng, Electrophoresis, 2008, 29, 3207.

22. E. Nemutlu, S. Kir, Journal of Pharmaceutical and Biomedical Analysis, 2003, 31, 393.

23. Y.H. Hsieh, S.J. Lin, S.H. Chen, Journal of Separation Science. 2006, 29, 1009.

24. S.E. Vignaduzzo, L. Vera-Candioti, P.M. Castellano, H.C. Goicoechea, T.S. Kaufman, Chromatographia, 2011, 74, 609.

25. A. Rusu, G. Hancu, G. Völgyi, G. Tóth, B. Noszál, A. Gyéresi, Journal of Chromatographic Science, 2014, 52, 919.

26. I. Ahmad, R. Bano, M.A. Sheraz, S. Ahmed, T. Mirza, S.A. Ansari, Acta Pharmaceutica, 2013, 63, 223.

27. Tuberculosis, 2008, 88, 119.

28. C.E., "European Pharmacopoeia" 9th edition, Council of Europe, Strasbourg, 2016, chapter Capillary electrophoresis.

29. M. El-Badry, Scientia Pharmaceutica, 2011, 79, 375.

30. J.M. Beale, J.H. Block, "Wilson and Gisvold's Textbook of Organic Medicinal and Pharmaceutical Chemistry". 12th edition, Lippincott Williams\&Wilkins, Philadelphia, 2011, chapter Appendix.

31. Romani LFA, Yoshida MI, Gomes ECL, Machado RR, Rodrigues FF, Coelho MM, M.A. Oliveira, M.B. Freitas-Marques, R.A.S. San Gil, W.N. Mussel. Journal of Pharmaceutical Analysis, 2018, 8, 103.

32. A. Rusu, S. Imre, E. Mircia, G. Hancu, Acta Medica Marisiensis, 2015, 61, 328.

33. "The Japanese Pharmacopoeia" English Version, 17th edition (the electronic version), The Ministry of Health, Labour and Welfare Ministerial, 2016, Ultraviolet visible reference spectra [Cited 2018 Oct 19] Available from http://jpdb.nihs.go.jp/ jp17e/

34. E.M. Hassan, Journal of Pharmaceutical and Biomedical Analysis, 2002, 27, 771. 
35. "The United States Pharmacopeial Convention Revision Bulletin", Official March 1, 2012, Meloxicam [Cited 2018 Oct 19] Available from https://www.uspnf.com/official-text/accelerated-revision-process/acceleratedrevision-history/meloxicam

36. S. Ahuja, M.I. Jimidar, "Capillary Electrophoresis Methods for Pharmaceutical Analysis", Academic Press Elsevier, Inc., Amsterdam, 2008, chapter 4.

37. European Medicines Agency, CPMP/ICH/381/95, ICH Q2 (R1) Validation of analytical procedures: text and methodology. 1995, [Cited 2018 Oct 19] Available from

http://www.ema.europa.eu/ema/index.jsp?curl=pages/regulation/general/ general_content_000768.jsp\&mid=WC0b01ac0580028e8d

38. R.C. Rowe, P.J. Sheskey, M.E. Quinn, "Handbook of pharmaceutical excipients. American Pharmacists Association." 6th edition, Pharmaceutical Press, American Pharmacists Association, London, Chicago, Washington, 2009.

39. G. Tiwari, R. Tiwari, Pharmaceutical Methods, 2010, 1, 25.

40. P. Antonoaea, A.G. Cârje, A. Ciurba, N. Todoran, A.R. Vlad, D.L. Muntean, Acta Medica Marisiensis, 2017, 63, 178. 